\title{
Living with Migraine in Canada - A National Community-Based Study
}

\author{
Kristianne Chelsea Altura, Scott B. Patten, Jeanne V. A. Williams, Kirsten M. Fiest, \\ Nathalie Jetté
}

\begin{abstract}
Objective: To develop a detailed profile of individuals living with migraine in Canada. Such a profile is important for planning and administration of services. Methods: The 2011-2012 Survey of Living with Neurological Conditions in Canada (SLNCC), a cross-sectional community-based survey, was used to examine a representative sample of migraineurs $(N=949)$ aged 15 years and older. Several health-related variables were examined (e.g., general health, health utility index (HUI) [a measure of health status and health-related quality of life, where dead $=0.00$ and perfect health $=1.00]$, stigma, depression, and social support). Respondents were further stratified by sex, age, and age of migraine onset. Weighted overall and stratified prevalence estimates and odds ratios, both with 95\% CIs, were used to estimate associations. Results: Overall, males had poorer health status compared with females (e.g., mean HUI was 0.67 in males vs. 0.82 in females; men had over two times the odds of their migraine limiting educational and job opportunities compared with females). Poorer health-related variables were seen in the older age groups (35-64 years/ $\geq 65$ years) compared with the 15-34-year age group. There were no differences between those whose migraine symptoms began before versus after the age of 20 years. Conclusions: In this Canadian sample, migraine was associated with worse health-related variables in men compared with women. However, both men and women were significantly affected by migraine across various healthrelated variables. Thus, it is important to improve clinical and public health interventions addressing the impact of migraine across individuals of all ages, sexes, and sociodemographic backgrounds.
\end{abstract}

RÉSUMÉ: Vivre avec la migraine au Canada : une étude nationale effectuée en milieu communautaire. Objectif: Élaborer un profil détaillé des individus aux prises avec la migraine au Canada. Un tel profil est important afin de planifier et d'administrer les services offerts. Méthodes: L'Enquête sur les personnes ayant des problèmes neurologiques au Canada (2011-2012), une enquête transversale effectuée en milieu communautaire, a été utilisée pour analyser un échantillon représentatif de patients atteints de migraine $(n=949)$ et âgés de 15 ans ou plus. Plusieurs variables touchant à la santé ont été examinées (p.ex. : l'état de santé général des patients ; le Health Utility Index [HUI], lequel mesure l'état de santé des individus, leur qualité de vie et en vertu duquel la mort $=0,00$ et un état de santé optimal $=1,00$; la stigmatisation, la présence de symptômes dépressifs et le fait de compter sur un soutien social). Les répondants ont été par la suite stratifiés en fonction de leur sexe, de leur âge et de leur âge au moment où ont débuté leurs symptômes migraineux. On a ensuite utilisé des estimations en matière de prévalence et des rapports des cotes dans le but de mesurer les associations. Tant ces estimations que ces rapports, notons-le, avaient été pondérés de façon générale et stratifiés en fonction d'un intervalle de confiance de $95 \%$. Résultats: Dans l'ensemble, les hommes ont montré un état de santé davantage précaire si on les compare aux femmes. Ainsi, leur HUI moyen était de 0,67 contre 0,82 chez les femmes. Ajoutons aussi que les hommes étaient deux fois plus susceptibles de voir leurs symptômes migraineux limiter leurs possibilités en matière d'emploi et d'éducation que les femmes. Par ailleurs, de moins bons indicateurs de santé ont été notés au sein des groupes plus âgés (35-64 ans / $\geq 65$ ans) en comparaison avec le groupe des 15-34 ans. Aucune différence notable n'a été observée entre les individus dont les symptômes migraineux se sont manifestés avant les 20 ans et ceux chez qui cela s'est passé après 20 ans. Conclusions: Au sein de cet échantillon canadien, on a donc remarqué que la migraine était davantage associée à des indicateurs négatifs de santé chez les hommes que chez les femmes. Cela dit, tant les femmes que les hommes étaient affectés de façon importante par la migraine si l'on tient compte de plusieurs variables touchant à la santé. En cela, il est important d'améliorer les interventions cliniques et de santé publique qui s'intéressent à l'impact de la migraine chez les individus de tout âge, et ce, peu importe leur sexe ou leur profil sociodémographique.

Keywords: Headache, Neurological, Cross-sectional study, Depression, Employment doi:10.1017/cjn.2019.3

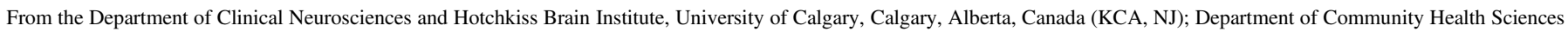

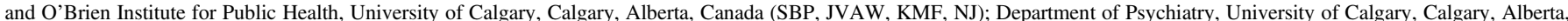

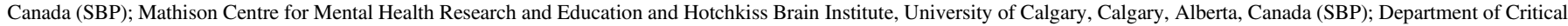
Care Medicine and Hotchkiss Brain Institute, University of Calgary, Calgary, Alberta, Canada (KMF)

Received October 9, 2018. Final Revisions Submitted December 18, 2018. Date of Acceptance January 10, 2019.

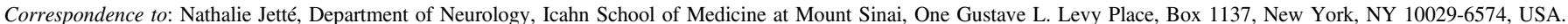
Email: Nathalie.jette@mssm.edu 


\section{INTRODUCTION}

Migraine is a leading global cause of years lived with disability (YLDs). ${ }^{1}$ An estimated $15 \%$ or approximately one billion people are affected by migraine across the world. ${ }^{1}$ Specifically, in Canada, the rate of migraine-caused YLDs slightly increased between 2006 and 2016; and in 2017, migraine was ranked second leading level-4 cause of YLDs, accounting for 770 YLDs per 100,000 (95\% uncertainty interval 496-1107)., ${ }^{2,3}$ In terms of overall disease burden, migraine is the sixth leading cause of disability-adjusted life years in Canada; the only conditions with a larger burden of disease being ischemic heart disease, low back pain, lung cancer, type 2 diabetes, and chronic obstructive pulmonary disease. ${ }^{3}$ Although generally not considered a life-threatening disorder, it can be very disabling and is associated with pain, decreased productivity and quality of life, and is a major contributor to ill health. ${ }^{4}$

With around $37 \%$ of migraineurs experiencing five or more headache-days per month and most migraineurs reporting severe impairment or requiring bed rest during attacks, migraine often greatly affects the individual in all aspects of life. ${ }^{5}$ Many medical and psychiatric comorbidities are also associated with migraine, including depression, epilepsy, and stroke. ${ }^{5}$ Furthermore, it has serious implications on the family as migraine can lead to postponed household work and canceled family and social activities. ${ }^{5}$ Migraine also has societal impacts. In the USA alone, its direct costs, including outpatient services, total as much as 17 billion dollars annually, while its indirect costs, which include costs of missing work and reduced productivity while working, amount to 13 billion dollars per year. ${ }^{5,6}$ Despite these burdens, migraine remains underdiagnosed and undertreated. ${ }^{7,8}$

Interestingly, migraine is twice as common in females than in males. ${ }^{9}$ Females are also more likely to develop depression, and having both migraine and depression is significantly associated with poor outcomes in migraineurs. ${ }^{10,11}$ As well, the prevalence of migraine in middle-aged groups is higher than those in adolescence and elderly groups ( $>60$ years). ${ }^{12}$ The middle-aged population is also a working group in their prime productive years, so any disruptions to their occupations may pose a large burden. It is unclear how age of migraine onset affects the individual, though one study found that those with a later age of onset had fewer attacks per month. ${ }^{13}$ Thus, the burdens of migraine may possibly be greater in the earlier-onset migraineur.

This study looks at the medical, psychosocial, and socioeconomic status of people with migraine in a national Canadian community-based sample. The aim of this study was to develop a detailed profile based on a large representative sample of Canadians with migraine. A descriptive profile of this nature is essential for setting priorities, anticipating needs in subgroups of patients, and for establishing a baseline against which to gauge future progress. The following should be taken into consideration regarding the broad, descriptive aims of the study: (1) due to the lack of data on many variables, many estimates are presented even in situations where these estimates were not used to evaluate or test specific hypotheses; (2) confidence intervals are reported for estimate because it allows for easier interpretation; and (3) even though some of the estimates (e.g., odds ratios) have null values, they should not be interpreted as statements of statistical significance in view of the multiple estimates presented. As these are $95 \%$ confidence intervals, and many such intervals are presented, the reported confidence intervals can be expected not to incorporate the true population value approximately $5 \%$ of the time.

\section{Methods}

\section{Data Source and Participants}

The Survey of Living with Neurological Conditions in Canada (SLNCC) is a national cross-sectional community-based survey of Canadians with neurological conditions. ${ }^{14}$ Administered using a computer-assisted telephone interview system, the SLNCC is a subset of the 2010 and 2011 population-based Canadian Community Health Survey (CCHS) and represents those respondents in the CCHS and household members who indicated the presence of at least one neurological condition. ${ }^{14}$ The CCHS uses multistage random cluster sampling and differing selection probabilities in different geographic regions and household sizes. To ensure that the sample was representative of the Canadian population, sampling weights were assigned to each participant to indicate the number of people that person represents in the Canadian population. Conducted from September 2011 to March 2012 by Statistics Canada and sponsored by the Public Health Agency of Canada, the SLNCC explored the experiences and health-related variables of its participants, such as their migraine diagnosis, social support, depression, and restriction of activities. ${ }^{14}$ Its target population was Canadians 15 years of age or older living in private households in the ten provinces with at least one of the following conditions: migraine, multiple sclerosis, epilepsy, cerebral palsy, spina bifida, hydrocephalus, muscular dystrophy, dystonia, Tourette's syndrome, Parkinson's disease, amyotrophic lateral sclerosis, Huntington's disease, Alzheimer's disease or other dementia, stroke, brain or spinal cord tumors, or spinal cord or brain injuries. ${ }^{14}$ The sampling frame excluded residents of the three territories, full-time members of the Canadian Forces, the institutionalized population, and persons living in remote areas, on reserves, and other Aboriginal settlements in the provinces. ${ }^{14}$ Overall, these exclusions represent $<3 \%$ of the Canadian population. ${ }^{14}$ The SLNCC sample had 4569 respondents, attaining an $81.6 \%$ response rate. ${ }^{14}$ This study used the subsample of participants with migraine $(n=949)$. With use of appropriate weights, estimates deriving from this sample are representative of the Canadian household population.

\section{Variables}

Baseline descriptive variables such as age, sex, and education were estimated. The following variables were also examined: migraine diagnosis, general health, health utility index (HUI), ${ }^{15}$ other neurological conditions, chronic conditions, incontinence, medication use, depression, stigma, social support, formal assistance, informal assistance, restriction of activities, work activities, out-of-pocket expenses, and income. To identify participants with migraine, the SLNCC asked the following question, “. . . do you have migraine headaches that have been diagnosed by a health professional?" to which participants answered "yes" or "no." HUI is a measure of health status and health-related quality of life based on a health utility approach and consists of eight attributes: vision, hearing, speech, ambulation, dexterity, emotion, cognition, and pain. ${ }^{15}$ Each attribute has five or six levels, ranging from highly impaired to normal. ${ }^{15}$ An overall score of 0.00 indicates death, whereas a 1.00 indicates perfect health. ${ }^{15}$ 
See Supplemental Appendix 1 for more detailed definitions of each variable. All variables were based on self-report.

\section{Data Analysis}

All analyses were conducted in STATA 12 with the replicate sampling weights provided by Statistics Canada. ${ }^{14,16}$ The sampling weights ensure population representativeness, ensure accurate variance estimation, and also incorporate adjustments for nonresponse (reducing the risk of selection bias). The estimates were bootstrapped to ensure accurate quantification of sampling variability. Proportions and $95 \%$ CIs were calculated for all categorical variables and were further stratified by sex (male/female), age $(15-34 / 35-64 / \geq 65$ years), and age of migraine onset $(<20 / \geq 20$ years). These cut-points for age were chosen based on the distribution of the sample. An <18-year-old age group was not feasible due to an insufficient number of participants to include in this group. Thus, data were stratified by late teenage to young adults (15-34 years), middle-aged to retirement (35-64 years), and postretirement ( $\geq 65$ years). For age of migraine onset, 20 years old was used as a cut-point as this was the median for the sample. Means and $95 \%$ CIs were calculated for all continuous variables and were also further stratified by sex, age, and age of migraine onset. Respondents with missing data were not included in analyses that used the variable with missing values (listwise deletion). However, participants tended to complete the questionnaire in its entirety, with the SLNCC having minimal partial non-response (missing one or more items) to any of its questions. ${ }^{14}$

Using a logistic regression model, odds ratios measuring the association of the various variables with sex, age, or age of migraine onset were generated for all variables. Wald tests based on the logistic regression analysis were used to determine statistical significance. Adjusted estimates were compared with unadjusted ones to identify confounding. An $\alpha$-value <.05 was set as the significance level for all statistical tests due to the exploratory aims of the study. Approval by an ethics review board was not required as the dataset is publicly available and use of this data is already regulated. ${ }^{17}$

\section{Results}

The SLNCC included 949 persons with migraine with an average age of 43.4 years $(95 \% \mathrm{CI}=41.6-45.2)$. There were 282 males and 667 females. The mean age of males and females were $46.2(95 \% \mathrm{CI}=42.6-49.8)$ and 42.8 years $(95 \% \mathrm{CI}=40.8-44.8)$, respectively. Overall, 59.0\% (95\% CI $=52.0-66.0)$ completed a certificate/diploma or degree above high school, with more women having completed a higher education than males $[60.4 \%$ $(95 \% \mathrm{CI}=52.5-68.3)$ vs. $52.6 \% \quad(95 \% \mathrm{CI}=40.1-65.1)]$; this difference was not significantly different (see Supplementary Table 1).

Clinical characteristics and general health-related variables of the overall migraine population and stratified by sex are reported in Table 1. Compared with females, a lower percentage of males were light-sensitive, limited in their ability to work or study (when suffering from a migraine headache), and reported that they were better due to medication(s). Males also had a poorer mean HUI $(0.67 ; 95 \% \mathrm{CI}=0.59-0.75)$ than females $(0.82 ; 95 \% \mathrm{CI}=0.79-0.86)$. A higher percentage of males had poor/fair general health and neurological comorbidities. Males had approximately three times the odds of having another neurological condition other than migraine. There was no significant difference between males and females regarding the use of prescription medications and whether they experienced medication side effects (see Supplementary Table 1).

Psychosocial health of the overall migraine population and stratified by sex are reported in Table 2 . There was no difference in depression between males $(23.6 \%$; 95\% CI $=15.3-31.8)$ and females $(21.5 \%$; 95\% CI $=15.3-27.7)$ (see Supplementary Table 1), keeping in mind that the prevalence of depression in the general population is higher in women than men. ${ }^{18,19}$ However, fewer males had available social support in terms of someone to take them to the doctor and so received informal assistance. From a stigma standpoint, although fewer males felt embarrassed sometimes/often/always compared with females about their condition, they had 2.3 times the odds of people seeming uncomfortable with them. A higher percentage of males were limited in educational and job opportunities due to their migraine and were unemployed. Overall, the males seemed to have poorer healthrelated variables than females (see Table 2).

There were 138 participants in the 15-34-year age group, 659 participants in the 35-64-year age group, and 152 participants in the $\geq 65$-year age group. The youngest group had the highest mean HUI (0.9) and had a higher percentage of informal assistance received (see Supplementary Table 2). Compared with the other age groups, a higher percentage of the middle-aged group felt considerably stressed out in life and had out-of-pocket expenses for rehabilitation therapy (see Supplementary Table 2). Compared with younger age groups, a higher percentage of the $\geq 65$-year age group had a neurological comorbidity, took prescription medications, felt stigmatized in terms of being avoided, received formal assistance, were unemployed, and had out-ofpocket expenses for assistive devices and homecare services (see Supplementary Table 2 ). The $\geq 65$-year age group also had the lowest mean HUI at $0.6(95 \% \mathrm{CI}=0.5-0.7)$ compared with the youngest age group $(p<.001)$ (see Supplementary Table 2). Overall, better health-related variables were seen in the younger age groups.

There were 344 participants in under 20 years as age of onset and 441 participants in over 20 years as age of onset. Compared to those with age of onset $\geq 20$ years, a significantly higher percentage of those with an earlier age of migraine onset felt limited in their educational opportunities (see Supplementary Table 3). For a majority of the health-related variables, however, there were no differences between earlier age and later age of migraine onset.

\section{Discussion}

The current study aimed to develop a detailed profile of individuals living with migraine in Canada. Migraine was found to be associated with a variety of health-related variables, many of which were worse for men compared with women, but not consistently. These findings were not limited to the middleaged group as the $\geq 65$-year age group demonstrated poorer health-related variables as well compared with the younger (15-34 years) group. Finally, there were no differences observed between early vs. late ( $>20$ years) onset migraine.

Although men have lower migraine prevalence, migraine was often associated with poorer medical and psychosocial health-related variables in men than in women in our study. One explanation for this could be that men generally seek less medical attention than women. ${ }^{20,21}$ Previous studies reported that among 
Table 1: Migraine clinical characteristics and general health-related state

\begin{tabular}{|c|c|c|c|c|}
\hline & \multirow{3}{*}{$\begin{array}{c}\text { Overall }(N=949) \\
\text { Proportion }(\%)(95 \% \mathrm{CI})^{*}\end{array}$} & \multicolumn{3}{|c|}{ Sex } \\
\hline & & \multirow{2}{*}{$\frac{\text { Male }(N=282)}{\text { Proportion }(\%)(95 \% \mathrm{CI})^{*}}$} & \multirow{2}{*}{$\begin{array}{c}\text { Female }(N=667) \\
\text { Proportion }(\%)(95 \% \mathrm{CI}) *\end{array}$} & \multirow[t]{3}{*}{ Odds ratio $(95 \% \mathrm{CI})$} \\
\hline & & & & \\
\hline \multicolumn{4}{|l|}{ Diagnosis } & \\
\hline \multicolumn{5}{|l|}{ Headaches } \\
\hline Nauseated & $90.7(87.2-94.3)$ & $85.8(76.3-95.2)$ & $91.8(88.2-95.5)$ & $0.54(0.24-1.21)$ \\
\hline Light-sensitive & $92.5(89.6-95.3)$ & 86.7 (78.9-94.5) & $93.7(90.7-96.8)$ & $0.44(0.20-0.97)$ \\
\hline Limited ability to work/study/other & $84.1(79.3-88.8)$ & $70.8(60.9-80.7)$ & $87.0(81.7-92.3)$ & $0.36(0.18-0.73)$ \\
\hline Mean age - first diagnosed (years) & $26.5(25.1-27.8)$ & $26.6(23.3-29.8)$ & $26.4(24.9-28.0)$ & N/A \\
\hline Mean age - first symptoms (years) & $23.1(21.7-24.4)$ & $24.2(20.6-27.8)$ & $22.8(21.3-24.3)$ & N/A \\
\hline \multicolumn{5}{|l|}{ Compared with when first diagnosed } \\
\hline Much better/somewhat better now & $51.1(43.9-58.4)$ & $47.8(35.9-59.6)$ & $51.8(43.5-60.2)$ & $0.85(0.47-1.55)$ \\
\hline About the same & $25.3(19.2-31.4)$ & $30.2(17.0-43.4)$ & $24.3(17.6-30.9)$ & $1.35(0.69-2.66)$ \\
\hline Much worse/somewhat worse now & $23.6(17.3-29.9)$ & $22.0(13.0-31.0)$ & $23.9(16.6-31.2)$ & $0.90(0.38-2.15)$ \\
\hline \multicolumn{5}{|c|}{$\begin{array}{l}\text { Reason why migraine is better now (among those } \\
\text { who reported their migraine to be better) }\end{array}$} \\
\hline Medication & $44.2(34.0-54.3)$ & $26.4(11.0-41.7)$ & $47.0(35.6-58.4)$ & $0.40(0.17-0.98)$ \\
\hline Surgery & $1.0(0.2-1.8)$ & $1.1(-0.6-2.8)$ & $1.0(0.1-1.9)$ & $1.13(0.05-24.72)$ \\
\hline In remission & $4.5(1.8-7.1)$ & $10.2(0.8-19.7)$ & $3.5(0.8-6.3)$ & $3.10(0.56-17.15)$ \\
\hline Complementary/alternative treatment & $8.8(2.6-14.9)$ & N/A & $10.0(2.9-17.1)$ & \\
\hline Rehabilitation therapy & $3.2(-0.3-6.7)$ & N/A & $3.6(-0.4-7.6)$ & \\
\hline Other medical treatment & $1.0(-1.1-3.1)$ & N/A & $1.1(-1.3-3.5)$ & \\
\hline Coping strategy & $33.9(24.8-42.9)$ & $38.8(17.8-59.8)$ & $33.1(23.2-42.9)$ & $1.28(0.46-3.58)$ \\
\hline Other & $30.9(22.1-39.7)$ & $45.3(26.5-64.1)$ & $28.6(18.9-38.3)$ & $2.07(0.78-5.48)$ \\
\hline \multicolumn{5}{|l|}{ General health (self-perceived) } \\
\hline Poor/fair & $20.0(15.3-24.7)$ & $30.7(20.1-41.2)$ & $17.6(12.5-22.8)$ & $2.07(1.10-3.88)$ \\
\hline Good/very good/excellent & $80.0(75.3-84.7)$ & $69.3(58.8-79.9)$ & $82.4(77.2-87.5)$ & $0.48(0.26-0.91)$ \\
\hline \multicolumn{5}{|l|}{$\begin{array}{l}\text { General health compared with } 1 \text { year ago } \\
\text { (self-perceived) }\end{array}$} \\
\hline Much better/somewhat better & $23.1(17.3-28.8)$ & $20.0(9.1-30.8)$ & $23.7(17.3-30.2)$ & $0.80(0.38-1.70)$ \\
\hline About the same & $60.2(53.4-66.9)$ & $67.7(56.4-79.1)$ & $58.5(50.9-66.1)$ & $1.49(0.82-2.71)$ \\
\hline Much worse/somewhat worse & $16.8(11.6-21.9)$ & $12.3(6.9-17.6)$ & $17.8(11.8-23.8)$ & $0.65(0.33-1.28)$ \\
\hline \multicolumn{5}{|l|}{$\begin{array}{l}\text { Amount of stress in life } \\
\text { (self-perceived) }\end{array}$} \\
\hline Not at all/not very/a bit stressful & $63.2(56.8-69.7)$ & $54.0(42.5-65.5)$ & $65.2(57.8-72.7)$ & $0.63(0.35-1.12)$ \\
\hline Quite a bit/extremely stressful & $36.8(30.3-43.2)$ & $46.0(34.5-57.5)$ & $34.8(27.3-42.2)$ & $1.60(0.89-2.86)$ \\
\hline Health utility index (mean) & $0.8(0.8-0.8)$ & $0.67(0.59-0.75)$ & $0.82(0.79-0.86)$ & N/A \\
\hline Depression $(\mathrm{PHQ}=9$ cut-point of 10$)$ & $21.9(16.5-27.3)$ & $23.6(15.3-31.8)$ & $21.5(15.3-27.7)$ & $1.12(0.57-2.23)$ \\
\hline
\end{tabular}

$\mathrm{PHQ}=$ Patient Health Questionnaire. Bold indicates significance at $p<0.05$. Logistic regression was used to generate odds ratios.

*Proportion is reported unless otherwise specified.

the general population, women have a significantly higher mean number of visits to their primary care physicians compared to men among both migraineurs and non-migraineurs. ${ }^{20,21}$ This lower health care utilization in men could be because they are less comfortable in seeking health care; and as a result, their migraines may be sub-optimally managed. ${ }^{22,23}$ Another reason why the impact of migraine may be greater in men is that they may not be taking appropriate medication or they may be responding differently to their medication. In the current study, there were fewer male participants who reported that their migraines were better due to medications $(26.0 \%$ in males vs. $47.0 \%$ in females). This could also be an indication that men are not adequately treating their migraines as it was previously shown that females with migraine are significantly more likely than males to use prescription and non-prescription medications for headache. ${ }^{21}$ Furthermore, there could be some biological reason such as differences in brain structure and function, hormones, neurotransmitters, or other biological substrates that 


\section{Table 2: Psychosocial variables}

\begin{tabular}{|c|c|c|c|c|}
\hline & \multirow[t]{2}{*}{ Overall $(N=949)$} & \multicolumn{3}{|c|}{ Sex } \\
\hline & & Male $(N=282)$ & Female $(N=667)$ & \\
\hline & Proportion $(\%)(95 \% \text { CI })^{*}$ & Proportion $(\%)(95 \% \text { CI })^{*}$ & Proportion $(\%)(95 \% \text { CI })^{*}$ & Odds ratio $(95 \% \mathrm{CI})$ \\
\hline \multicolumn{5}{|l|}{ Stigma (self-perceived) } \\
\hline \multicolumn{5}{|l|}{ "People seemed uncomfortable with me" } \\
\hline Never/rarely & $82.5(77.7-87.4)$ & $71.1(61.4-80.8)$ & $84.9(79.5-90.4)$ & $0.44(0.21-0.90)$ \\
\hline Sometimes/often/always & $17.5(12.6-22.3)$ & $28.9(19.2-38.6)$ & $15.1(9.6-20.5)$ & $2.29(1.11-4.73)$ \\
\hline \multicolumn{5}{|l|}{ "People avoided me" } \\
\hline Never/rarely & $91.6(88.7-94.4)$ & $88.3(80.7-95.8)$ & $92.3(89.2-95.4)$ & $0.63(0.28-1.40)$ \\
\hline Sometimes/often/always & $8.4(5.6-11.3)$ & $11.7(4.2-19.3)$ & $7.7(4.6-10.8)$ & $1.59(0.72-3.53)$ \\
\hline \multicolumn{5}{|l|}{ "I felt left out of things" } \\
\hline Never/rarely & $71.0(64.3-77.7)$ & $72.5(62.6-82.3)$ & $70.7(62.9-78.5)$ & $1.09(0.58-2.06)$ \\
\hline Sometimes/often/always & $29.0(22.3-35.7)$ & $27.5(17.7-37.4)$ & $29.3(21.5-37.1)$ & $0.92(0.49-1.73)$ \\
\hline \multicolumn{5}{|l|}{ "I felt embarrassed" } \\
\hline Never/rarely & $83.0(77.7-88.3)$ & $91.5(84.9-98.2)$ & $81.1(75.0-87.3)$ & $2.51(1.19-5.30)$ \\
\hline Sometimes/often/always & $17.0(11.7-22.3)$ & $8.5(1.8-15.1)$ & $18.9(12.7-25.0)$ & $0.40(0.19-0.84)$ \\
\hline \multicolumn{5}{|l|}{ Availability of social support if needed } \\
\hline \multicolumn{5}{|l|}{$\begin{array}{l}\text { Someone to confide in or talk to about } \\
\text { yourself or your problems }\end{array}$} \\
\hline None/a little of the time & $10.1(6.3-13.9)$ & $8.7(1.6-15.9)$ & $10.4(6.1-14.8)$ & $0.82(0.32-2.11)$ \\
\hline Some/most/all of the time & $89.9(86.1-93.7)$ & $91.3(84.1-98.4)$ & $89.6(85.2-93.9)$ & $1.21(0.47-3.11)$ \\
\hline \multicolumn{5}{|l|}{ Someone to do something enjoyable with } \\
\hline None/a little of the time & $7.1(4.3-9.9)$ & $5.2(0.2-10.2)$ & $7.5(4.3-10.8)$ & $0.67(0.22-2.10)$ \\
\hline Some/most/all of the time & $92.9(90.1-95.7)$ & $94.8(89.8-99.8)$ & $92.5(89.2-95.7)$ & $1.49(0.48-4.64)$ \\
\hline \multicolumn{5}{|l|}{ Someone to take you to the doctor } \\
\hline None/a little of the time & $4.4(2.3-6.5)$ & $10.4(1.1-19.7)$ & $3.1(1.6-4.7)$ & $3.59(1.30-9.93)$ \\
\hline Some/most/all of the time & $95.6(93.5-97.7)$ & $89.6(80.3-98.9)$ & $96.9(95.3-98.4)$ & $0.28(0.10-0.77)$ \\
\hline \multicolumn{5}{|l|}{ Someone to turn to for help in an emergency } \\
\hline None/a little of the time & $2.5(1.1-3.8)$ & $4.8(-0.1-9.8)$ & $1.9(0.6-3.3)$ & $2.56(0.78-8.48)$ \\
\hline Some/most/all of the time & $97.5(96.2-98.9)$ & $95.2(90.2-100.1)$ & $98.1(96.7-99.4)$ & $0.39(0.12-1.29)$ \\
\hline \multicolumn{5}{|l|}{ Formal assistance } \\
\hline Formal assistance received (past $12 \mathrm{mo}$.) & $2.6(1.5-3.7)$ & $4.2(0.8-7.6)$ & $2.3(1.1-3.4)$ & $1.91(0.79-4.61)$ \\
\hline \multicolumn{5}{|l|}{ Informal assistance } \\
\hline Informal assistance received (past $12 \mathrm{mo}$.) & $35.7(29.4-42.0)$ & $23.8(14.8-32.8)$ & $38.3(30.8-45.8)$ & $0.50(0.27-0.94)$ \\
\hline \multicolumn{5}{|l|}{ Restriction of activities } \\
\hline \multicolumn{5}{|l|}{ Condition limited educational opportunities } \\
\hline Not at all/a little bit & $82.8(78.2-87.3)$ & $73.3(62.7-83.9)$ & $84.8(79.8-89.9)$ & $0.49(0.25-0.98)$ \\
\hline Moderately/quite a bit/extremely & $17.2(12.7-21.8)$ & $26.7(16.1-37.3)$ & $15.2(10.1-20.2)$ & $2.04(1.02-4.07)$ \\
\hline \multicolumn{5}{|l|}{ Condition limited job opportunities } \\
\hline Not at all/a little bit & $81.1(76.6-85.5)$ & $70.7(61.1-80.2)$ & $83.4(78.4-88.3)$ & $0.48(0.27-0.87)$ \\
\hline Moderately/quite a bit/extremely & $18.9(14.5-23.4)$ & $29.3(19.8-38.9)$ & $16.7(11.7-21.6)$ & $2.08(1.15-3.76)$ \\
\hline \multicolumn{5}{|l|}{ Condition limited a good night's sleep } \\
\hline Not at all/a little bit & $54.8(47.7-61.9)$ & $48.4(36.5-60.4)$ & $56.2(48.1-64.4)$ & $0.73(0.41-1.32)$ \\
\hline Moderately/quite a bit/extremely & $45.2(38.1-52.3)$ & $51.6(39.6-63.5)$ & $43.8(35.6-51.9)$ & $1.37(0.76-2.46)$ \\
\hline \multicolumn{5}{|l|}{ Overall, how much condition affects life } \\
\hline Not at all/a little bit & $57.8(51.1-64.4)$ & $56.3(44.4-68.2)$ & $58.1(50.5-65.7)$ & $0.93(0.52-1.65)$ \\
\hline Moderately/quite a bit/extremely & $42.2(35.6-48.9)$ & $43.7(31.8-55.6)$ & $41.9(34.3-49.5)$ & $1.08(0.61-1.92)$ \\
\hline
\end{tabular}


Table 2: (Continued)

\begin{tabular}{|c|c|c|c|c|}
\hline & \multirow[t]{2}{*}{ Overall $(N=949)$} & \multicolumn{3}{|c|}{ Sex } \\
\hline & & Male $(N=282)$ & Female $(N=667)$ & \\
\hline & Proportion (\%) $(95 \% \mathrm{CI}) *$ & Proportion (\%) $(95 \% \mathrm{CI})^{*}$ & Proportion (\%) $(95 \% \mathrm{CI})^{*}$ & Odds ratio $(95 \% \mathrm{CI})$ \\
\hline \multicolumn{5}{|l|}{ Limitation in usual activities (all) } \\
\hline Limited in at least one usual activity & $92.6(89.3-96.0)$ & $90.5(83.9-97.0)$ & $93.1(89.3-96.9)$ & $0.70(0.18-2.69)$ \\
\hline Did not experience any limitation & $7.4(4.0-10.7)$ & $9.5(3.0-16.1)$ & $6.9(3.1-10.7)$ & $1.42(0.37-5.43)$ \\
\hline \multicolumn{5}{|l|}{ Work activities } \\
\hline \multicolumn{5}{|l|}{ Working status } \\
\hline Part-time & $17.2(11.0-23.4)$ & $3.1(-2.4-8.6)$ & $19.4(12.3-26.6)$ & $0.13(0.03-0.64)$ \\
\hline Full-time & $82.8(76.6-89.0)$ & $96.9(91.4-102.4)$ & $80.6(73.4-87.7)$ & $7.56(1.57-36.40)$ \\
\hline \multicolumn{5}{|l|}{ Working status past week } \\
\hline $\begin{array}{l}\text { Did not have a job/permanently } \\
\text { unable to work }\end{array}$ & $33.4(27.4-39.4)$ & $48.7(36.7-60.7)$ & $30.1(23.2-36.9)$ & $2.21(1.21-4.05)$ \\
\hline $\begin{array}{l}\text { Worked at job or business/had a job } \\
\text { but was absent }\end{array}$ & $66.6(60.6-72.6)$ & $51.3(39.3-63.3)$ & $69.9(63.1-76.8)$ & $0.45(0.25-0.83)$ \\
\hline \multicolumn{5}{|l|}{ Out-of-pocket expenses } \\
\hline Medication & $55.5(49.0-62.0)$ & $48.5(36.7-60.3)$ & $57.0(49.6-64.4)$ & $0.71(0.40-1.26)$ \\
\hline Assistive devices & $2.6(1.3-3.8)$ & $4.5(1.1-7.9)$ & $2.1(0.8-3.5)$ & $2.15(0.85-5.45)$ \\
\hline Rehabilitation therapy & $16.2(11.3-21.1)$ & $18.6(8.6-28.7)$ & $15.7(10.3-21.0)$ & $1.23(0.47-3.23)$ \\
\hline Home care services & $1.2(0.5-1.8)$ & $2.2(-0.3-4.6)$ & $0.9(0.4-1.5)$ & $2.29(0.55-9.51)$ \\
\hline \multicolumn{5}{|l|}{ Income } \\
\hline \multicolumn{5}{|l|}{$\begin{array}{l}\text { Total household income (before } \\
\text { taxes and deductions) }\end{array}$} \\
\hline$<\$ 60,000$ & $40.2(33.2-47.2)$ & $39.9(27.0-52.9)$ & $40.3(32.3-48.3)$ & $0.99(0.52-1.88)$ \\
\hline$\geq \$ 60,000$ & $59.8(52.8-66.8)$ & $60.1(47.1-73.0)$ & $59.7(51.7-67.7)$ & $1.01(0.53-1.93)$ \\
\hline
\end{tabular}

Bold indicates significance at $p<0.05$. Logistic regression was used to generate odds ratios.

*Proportion is reported unless otherwise specified.

could explain these sex differences. ${ }^{24,25}$ For instance, a magnetic resonance imaging study found that female migraineurs had thicker posterior insula and precuneus cortices compared with male migraineurs and healthy controls. ${ }^{24}$ Whether biology is responsible for the sex differences remains unclear, but these are areas that require further exploration. Finally, though migraine limited job opportunities more in men than women, men were more likely to be employed, which may explain these differences.

As for the age-stratified data, the middle-aged group did not have worse health-related variables in general compared with the other age groups, with some exceptions. Poorer health-related variables were seen in the older age groups as a whole. Various reasons can explain why older individuals are worse off compared with the 15-34-year age group. For instance, older people tend to have more chronic conditions, which can significantly affect different aspects of their health. As a result, older people tend to take more medications compared with younger individuals, which may lead to side effects and poorer outcomes. ${ }^{26,27}$

The impact of migraine was similar regardless of age of migraine onset ( $<20$ or $\geq 20$ years). An age of onset of 20 years was used as this was the median for the sample.

This study has several strengths. The total sample size was large and representative, which allowed for a more detailed investigation of individuals living with migraine. As well, a variety of health-related variables were evaluated so that a thorough assessment of living with migraine could be examined. However, the study is not without limitations. Firstly, the study did not include a control group of participants without migraine; and because we only examined those with migraine, wide confidence intervals were generated. Also, since adjustments were not made to $p$-values, there might have been a resulting risk of type 1 error. Due to the multiple comparisons, the results require replication. Another limitation is that the SLNCC did not have a migraine severity variable, so it was not possible to stratify the data by migraine severity. The fact that the study design was cross-sectional also did not allow us to establish any causal inferences as to why men in general have poorer medical and psychosocial health-related variables compared with women. A major limitation of the study is that depression and other migraine comorbidities could have produced confounding effects (e.g., some of the negative health status seen in individuals with migraine might have been due to migraine comorbidities). Thus, detailed clinical assessments would be needed to address this. The main strength of the current study is our populationrepresentative sample allowing for a highly descriptive study, but the lack of detailed information about confounders means that the mechanisms mediating or accounting for the associations between migraine and negative health states need to be examined in future studies. Furthermore, though self-report can be excellent in some situations, the accuracy of self-report for the variables 
examined in this study was not examined for every variable. Thus, some misclassification may have occurred. It has also been shown that $98 \%$ of patients diagnosed with migraine by primary care physicians had migraine. ${ }^{28}$ However, $82 \%$ of patients with a non-migraine diagnosis were found to have migraine. ${ }^{28}$ Thus, although participants who self-reported as having been diagnosed with migraine most likely have migraine, there could have been other individuals with migraine who did not have a migraine diagnosis and were not captured by the SLNCC. Additionally, the results from this high-income country may not be generalizable to low- or middle-income countries or to other high-income countries with different health care systems. Finally, there are a number of findings that were unexpected and unexplained; for example, what treatments classified as "other" are reportedly making migraines better? Some of these findings require replication, especially in view of the multiple estimates reported, and further studies to explore the etiology of these findings.

In summary, our findings show that migraine is associated with a number of poor health-related variables. Men and older age groups with migraine often had poorer health-related variables compared with women and young migraineurs, respectively, but there were no differences between migraineurs with an early age of onset and those with a late age of onset. Though this study presents preliminary findings that warrant confirmation from further studies, it also highlights the importance of raising awareness about the burden of migraine so that current/future interventions that alleviate the burden and impact of migraine may be improved/developed for all those living with migraine.

\section{ACKNOWLEDGMenTs}

This analysis was based upon data collected by Statistics Canada. However, the analysis and interpretations presented do not reflect the views of Statistics Canada. Thank you to the Prairie Regional Research Data Center analysts - Rebecca Williams and Charlie Victorino - for providing assistance during the research process.

\section{FUNDING}

This research did not receive any financial support from public or commercial funding agencies.

\section{CONFLict of INTEREST}

Nathalie Jetté was the holder of a Canada Research Chair Tier 2 in Neurological Health Services Research at the time of this study and received, during this study, research support from the Canadian Institutes of Health Research, Alberta Health, the Hotchkiss Brain Institute, the University of Calgary Cumming School of Medicine, and the National Institutes of Health for work unrelated to this project. Scott B. Patten receives research support from the Hotchkiss Brain Institute and holds the Cuthbertson and Fischer Chair in Pediatric Mental Health at the University of Calgary. Kristianne Chelsea Altura, Jeanne V.A. Williams, and Kirsten M. Fiest have no conflicts of interest to report.

\section{Statement of Authorship}

KCA: study concept and design, analysis and interpretation of the data, preparation of the initial manuscript draft; SBP: study concept and design, analysis and interpretation of data, critical revision of the manuscript for intellectual content; JVAW: analysis and interpretation of data, critical revision of the manuscript for intellectual content; KMF: analysis and interpretation of data, critical revision of the manuscript for intellectual content; $\mathrm{NJ}$ : study concept and design, analysis and interpretation of data, critical revision of the manuscript for intellectual content, and study supervision.

\section{SuPPlementary Material}

To view supplementary material for this article, please visit https://doi.org/10.1017/cjn.2019.3.

\section{REFERENCES}

1. Vos T, Allen C, Arora M, et al. Global, regional, and national incidence, prevalence, and years lived with disability for 310 diseases and injuries, 1990-2015: a systematic analysis for the Global Burden of Disease Study 2015. The Lancet. 2016;388: 1545-602.

2. Lang JJ, Alam S, Cahill LE, et al. Global burden of disease study trends for Canada from 1990 to 2016. CMAJ. 2018;190: E1296-304.

3. IHME. GBD Compare [online]. Available at: https://vizhub.health data.org/gbd-compare/. Accessed December 11, 2018.

4. Malone CD, Bhowmick A, Wachholtz AB. Migraine: treatments, comorbidities, and quality of life, in the USA. J Pain Res. 2015; 8:537-47.

5. Bigal ME, Lipton RB. The epidemiology, burden, and comorbidities of migraine. Neurol Clin. 2009;27:321-34.

6. Mennini FS, Gitto L, Martelletti P. Improving care through health economics analyses: cost of illness and headache. J Headache Pain. 2008;9:199-206.

7. Cevoli S, D'Amico D, Martelletti P, et al. Underdiagnosis and undertreatment of migraine in Italy: a survey of patients attending for the first time 10 headache centres. Cephalalgia. 2009;29: 1285-93.

8. Pracilio VP, Silberstein S, Couto J, et al. Measuring migrainerelated quality of care across 10 health plans. Am J Manag Care. 2012;18:e291-99.

9. Woldeamanuel Y, Cowan R. Worldwide migraine epidemiology: systematic review and meta-analysis of 302 community-based studies involving 6, 216, 995 participants (P6. 100). Neurology. 2016;86:P6-100.

10. Kuehner C. Gender differences in unipolar depression: an update of epidemiological findings and possible explanations. Acta Psychiat Scand. 2003;108:163-74.

11. Jette N, Patten S, Williams J, Becker W, Wiebe S. Comorbidity of migraine and psychiatric disorders-A national population-based study. Headache. 2008;48:501-16.

12. Lipton RB, Bigal ME, Diamond M, Freitag F, Reed ML, Stewart WF. Migraine prevalence, disease burden, and the need for preventive therapy. Neurology. 2007;68:343-9.

13. Asuni C, Manchia M, Deidda A, Stochino ME, Cherchi A, Del Zompo M. Mixture analysis of age at onset in migraine without aura: evidence for three subgroups. Headache. 2010;50: 1313-9.

14. StatisticsCanada. Survey on Living with Neurological Conditions in Canada (SLNCC) [online]. Available at: http://www23. statcan.gc.ca/imdb/p2SV.pl?Function=getSurvey\&SDDS=5182. Accessed September 18, 2015.

15. Feeny D, Furlong W, Torrance GW, et al. Multiattribute and singleattribute utility functions for the health utilities index mark 3 system. Med Care. 2002;40:113-28.

16. Stata statistical software [computer program]. Version 12.0. College Station, TX: StataCorp LP, 2012.

17. InteragencyAdvisoryPanelonResearchEthics. TCPS 2 - Tri-Council Policy Statement: Ethical Conduct for Research Involving Humans [online]. Available at: http://www.pre.ethics.gc.ca/eng/ policy-politique/initiatives/tcps2-eptc2/Default/. Accessed June 1, 2018. 
18. Bromet E, Andrade LH, Hwang I, et al. Cross-national epidemiology of DSM-IV major depressive episode. BMC Med. 2011;9:90.

19. Patten SB, Williams JV, Lavorato DH, Wang JL, McDonald K, Bulloch AG. Descriptive epidemiology of major depressive disorder in Canada in 2012. Can J Psychiatry. 2015;60:23-30.

20. Bertakis KD, Azari R, Helms LJ, Callahan EJ, Robbins JA. Gender differences in the utilization of health care services. J Fam Practice. 2000;49:147-52.

21. Buse DC, Loder EW, Gorman JA, et al. Sex differences in the prevalence, symptoms, and associated features of migraine, probable migraine and other severe headache: results of the American Migraine Prevalence and Prevention (AMPP) study. Headache. 2013;53:1278-99.

22. Hennessy M, Mannix-McNamara P. Gendered perspectives of men's health and help seeking: implications for public health and health promotion. Int J Med Health Sci Res. 2014;1:13-28.
23. Himmelstein MS, Sanchez DT. Masculinity impediments: internalized masculinity contributes to healthcare avoidance in men and women. J Health Psychol. 2016;21:1283-92.

24. Maleki N, Linnman C, Brawn J, Burstein R, Becerra L, Borsook D. Her versus his migraine: multiple sex differences in brain function and structure. Brain. 2012;135:2546-59.

25. Borsook D, Erpelding N, Lebel A, et al. Sex and the migraine brain. Neurobiol Dis. 2014;68:200-14.

26. Hubbard RE, O'Mahony MS, Woodhouse KW. Medication prescribing in frail older people. Eur J Clin Pharmacol. 2013;69:319-26.

27. Maher RL, Hanlon J, Hajjar ER. Clinical consequences of polypharmacy in elderly. Expert Opin Drug Saf. 2014;13:57-65.

28. Tepper SJ, Dahlof CG, Dowson A, et al. Prevalence and diagnosis of migraine in patients consulting their physician with a complaint of headache: data from the landmark study. Headache. 2004;44: $856-64$. 